\title{
Macro-scale complexity of nano- to micro-scale architecture of olivine crystals through an iodine vapour transport mechanism
}

\author{
RAYMOND L D WHITBY ${ }^{\mathrm{a}, \mathrm{b}, *}$, TAKAHIRO FUKUDA ${ }^{\mathrm{b}}$ and TORU MAEKAWA ${ }^{\mathrm{b}}$ \\ ${ }^{a}$ Nanoscience and Nanotechnology Group, Faculty of Science and Engineering, University of Brighton, Lewes Road, \\ Brighton, BN2 4GJ, United Kingdom \\ bio-Nano Electronics Research Centre, Toyo University, 2100 Kujirai, Kawagoe, 350-8585 Saitama, Japan
}

MS received 14 March 2012

\begin{abstract}
The production of nano- to micro-scale olivine (magnesium and iron silicate) crystals has been achieved at relatively low temperatures through an iodine vapour transport of the metal onto amorphous silicon dioxide. The process occurs down a temperature gradient from 800 to $600{ }^{\circ} \mathrm{C}$ yielding high quality crystals with long range crystallinity, highly complex interconnectivity and intricate macroscale architecture. Scanning electron microscopy (SEM) imaging of the substrate before and after the reaction reveals that the amorphous silicon oxide species is mobile, due to the lack of correlation between the silicon oxide layer and the final olivine particles, leading to a vapour-liquid-solid or vapour-solid growth mechanism. This technique demonstrates a facile, low temperature synthetic route towards olivine crystals with nano- to micro-scale dimensions.
\end{abstract}

Keywords. Nanocrystals; forsterite; fayalite; iodine vapour transport; architecture.

\section{Introduction}

In order to obtain pure olivine, a number of production methods have been developed. These include direct heating of, for forsterite, $\mathrm{MgO}$ and $\mathrm{SiO}_{2}$ powders (Jander and Wuhrer 1936; Brindley and Hayama 1965), co-precipitation (Yamaguchi et al 1976) and sol-gel techniques (Kazakos et al 1990). Typically the $\mathrm{MgO}$ and $\mathrm{SiO}_{2}$ samples are heated up to $1550{ }^{\circ} \mathrm{C}$, where the $\mathrm{MgO}$ diffuses into the $\mathrm{SiO}_{2}$ particles to form forsterite, but can further react with excess $\mathrm{SiO}_{2}$ to form enstatite when the reaction is heated to over $1200{ }^{\circ} \mathrm{C}$ (Brindley and Hayama 1965; Kazakos et al 1990; Mitchell et al 1999). The stochiometry is better controlled via sol-gel techniques, with the onset of forsterite crystallisation at around $550{ }^{\circ} \mathrm{C}$ occurring in small crystalline domains (Burlitch et al 1991; Tsai 2003), but results indicate the presence of magnesia and enstatite within the crystal samples. Nanoscale crystal formation of forsterite has also been achieved elsewhere, by direct solid combination resulting in dendritic crystals (Faure et al 2003), chemical catalysis resulting in fishbone-like structures (Xie et al 2004) or wires (Zhang et al 2010), the sol-gel method to generate nanopowder (Kamran et al 2011) and ball milling the precursors and subsequent heating to generate nanocrystalline composites (Tavangarian and Emadi 2011).

Iodine vapour transport has historically been a useful method for growing crystals (e.g. Rimmington and Balchin 1974) and we have reported the first application of iodine vapour transport growth of nanocrystals of forsterite (Whitby

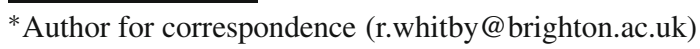

et al 2004). Herein, we elaborate on the diversity of architecture exhibited by both the magnesium and iron silicate (olivine) systems. Characterization reveals that these structures closely match those of forsterite and fayalite, thus representing a low temperature synthetic route towards olivine crystals, as well as their production with nano- to micro-scale dimensions.

\section{Experimental}

Typically, Mg or Fe powder (Alfa, 99.8\% - 325 mesh, $85 \mathrm{mg}$ ) was finely mixed with $\mathrm{I}_{2}$ (Aldrich, $99.9+\%, 15 \mathrm{mg}$ ) in an $85: 15$ ratio. The powder was placed in a quartz boat, within a quartz tube (internal diameter $14 \mathrm{~mm}$ ), approximately $20 \mathrm{~cm}$ from a horizontal quartz substrate containing a fine layer of amorphous silicon oxide via thermal deposition. The quartz tube was sealed under a He atmosphere $(0.5 \mathrm{~atm})$ and placed within a 3-stage furnace. The mixed powders were heated to $800{ }^{\circ} \mathrm{C}$ and the substrate end of the tube heated to $600{ }^{\circ} \mathrm{C}$, thus obtaining a temperature gradient of ca. $10{ }^{\circ} \mathrm{C} \mathrm{cm}-1$. The reaction was left for $48-72 \mathrm{~h}$ after which the furnace was allowed to cool to room temperature over a period of $24 \mathrm{~h}$. The quartz substrate, containing a grey deposit, was extracted for scanning electron microscopy (SEM) analysis and a small amount of crystal deposit was carefully removed from the substrate and prepared for transmission electron microscopy (TEM) investigations. A number of crystals were also observed growing on the walls of the reaction tube at the substrate end and a brown deposit collected at the tip end of the reaction tube. 


\section{Results and discussion}

\subsection{Characterization}

Figure 1(a) shows a low magnification SEM image of the quartz substrate after completion of reaction. There is a random distribution of structures on top of the substrate that have a diameter of 30-70 $\mu \mathrm{m}$ and the side-profile (figure 1b) shows that the height also varies up to $50 \mu \mathrm{m}$. Typically, each macro-structure comprises numerous, tightly packed leaves protruding from a central core. These leaves had a high aspect ratio with their heights and widths varying up to $50 \mu \mathrm{m}$. The broad leaves terminate at an apex with an angle varying between 70 and 130 degrees and have a thickness less than $20 \mathrm{~nm}$.

Figure 2(a) shows a TEM image of the fan-like crystal structure typifying a 2-D transmission view of the 3-D geometry. The width of the leaves vary considerably and is not always uniform down the length of the leaf-like crystal. The length of the leaf-like crystals also varies widely from ca. $100 \mathrm{~nm}$ to $35 \mu \mathrm{m}$, always terminating in a triangular apex. Not all the crystal planes run to the full width or full length of the leaf-like crystals, such that the layers are staggered packed and the thickness of the crystal reduces towards its edges. This can be seen by the different termination lines at the edges of the main crystal leaf (figure 2(b) white arrows).

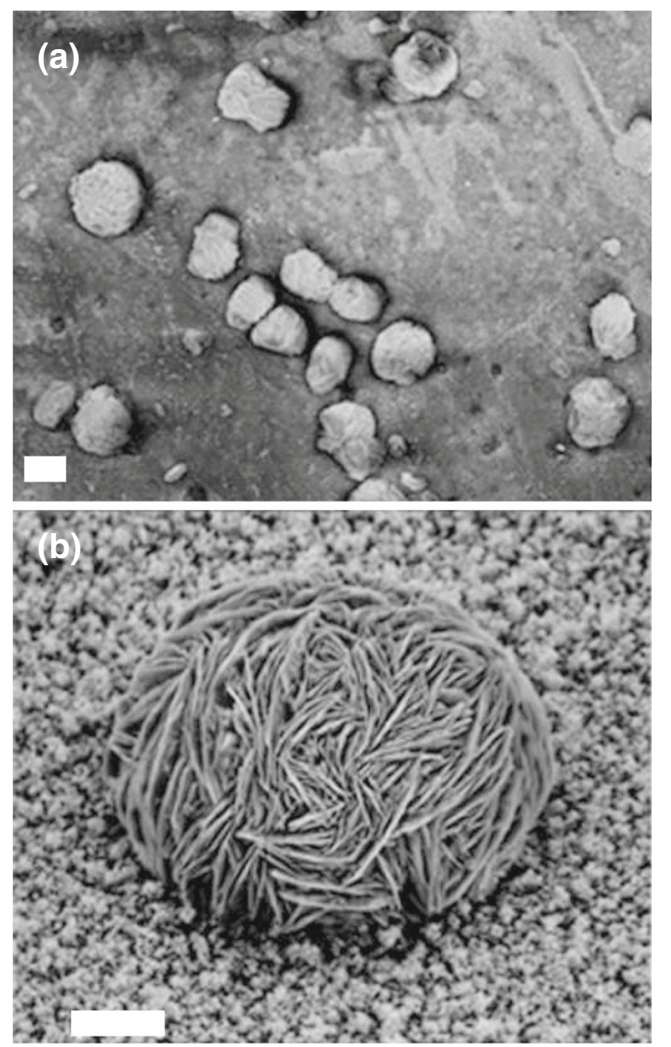

Figure 1. (a) SEM image of crystal deposits on the substrate and (b) an SEM image of the cabbage-like crystal (scale bars $=30 \mu \mathrm{m}$ and $10 \mu \mathrm{m}$ respectively).
Figure 2(c) shows a TEM image taken parallel to the [100] zone axis revealing a uniform crystal lattice structure. Previous results showed that the crystal structure was consistent with that of Forsterite $\left(\mathrm{Mg}_{2} \mathrm{SiO}_{4}\right)$ with an orthorhombic unit cell possessing a $P_{\text {bnm }}$ space group (No. 62) and lattice parameters of $a=4.7, b=9.9$ and $c=5.8 \AA$ (Whitby et al 2004). The lattice fringes are separated by ca. 0.26 and
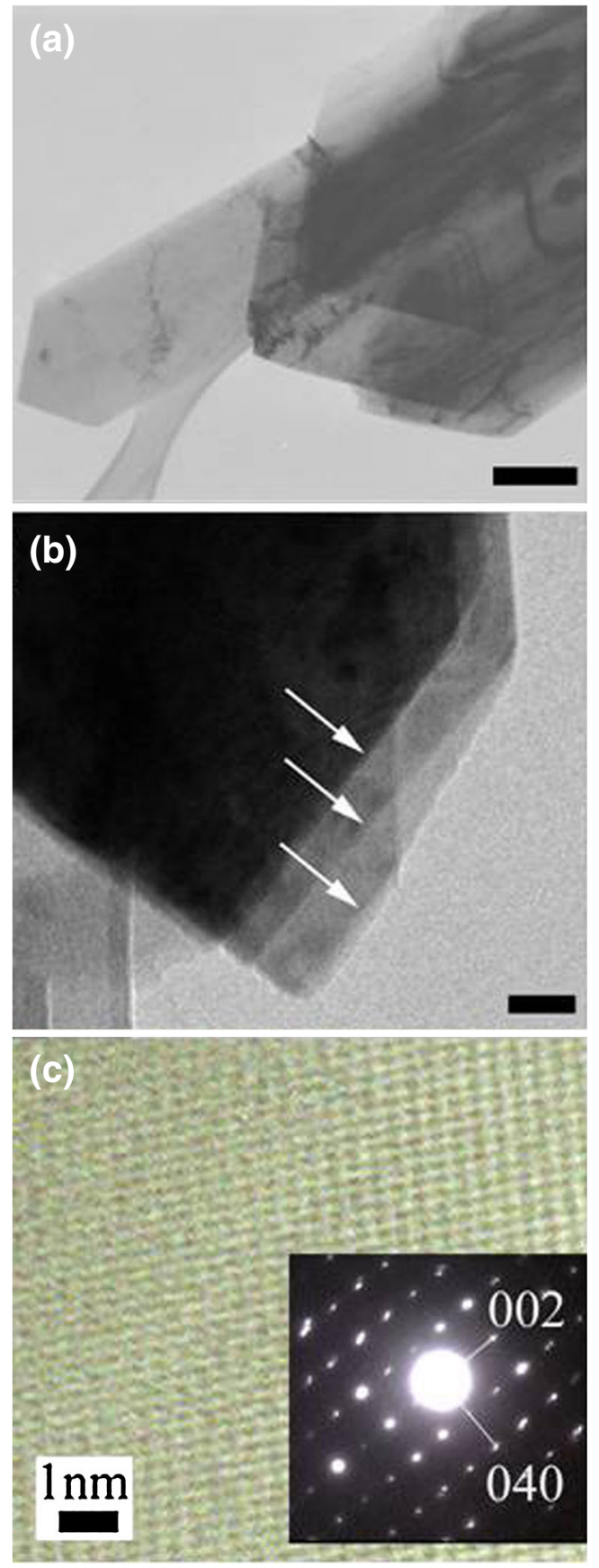

Figure 2. (a) TEM image of individual leaf-like forsterite crystals $($ scale bar $=500 \mathrm{~nm}),(\mathbf{b})$ higher magnification of an individual leaflike crystal reveals variation in crystal width (white arrows depicting the termination edges, scale bar $=100 \mathrm{~nm}$ ) and (c) TEM image reveals the uniform lattice structure of these forsterite crystals with a selected area diffraction pattern (insert). 

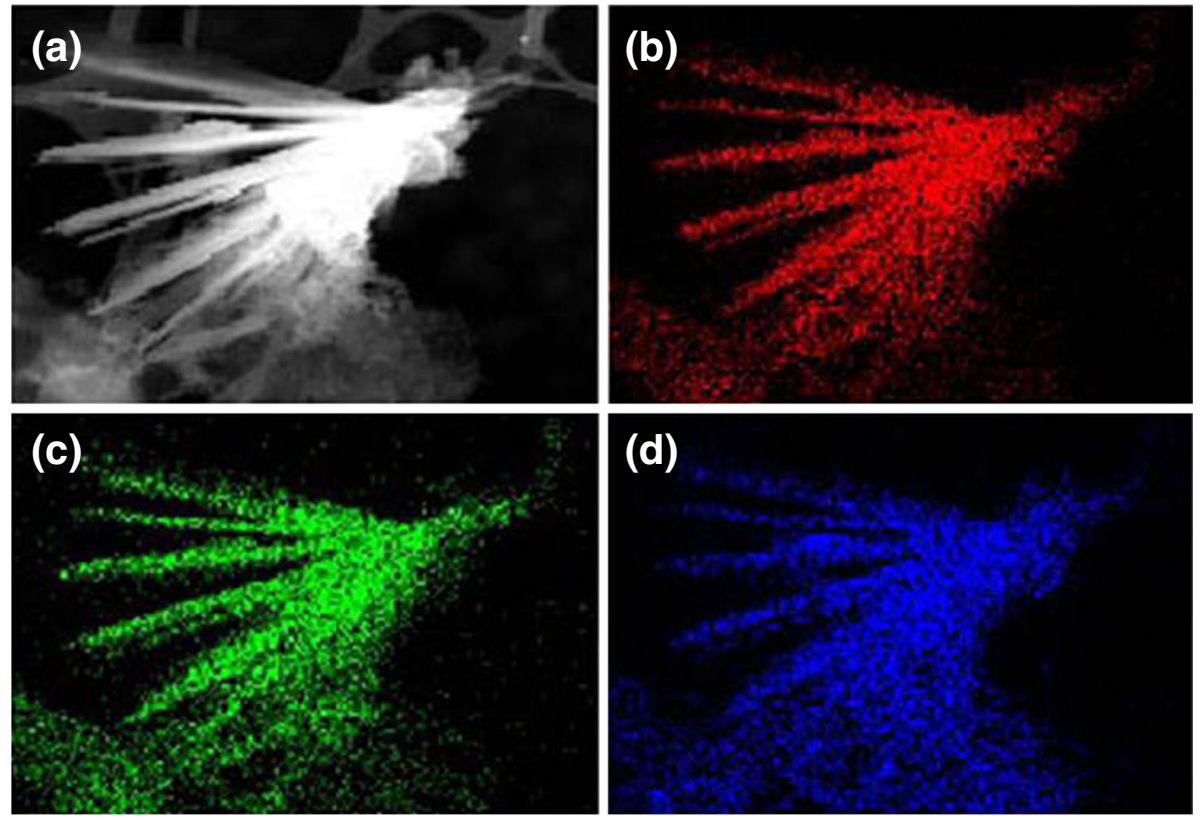

Figure 3. EDX mapping analysis of (a) the forsterite crystals reveal the presence of (b) Si (red), (c) $\mathrm{Mg}$ (green) and (d) $\mathrm{O}$ (blue).

$0.38 \mathrm{~nm}$ respectively, corresponding to the $022(d=2.58 \mathrm{~nm})$ and $02-1(d=3.88 \mathrm{~nm})$ reflections.

Energy Dispersive X-ray (EDX) (figure 3) of the macrostructure revealed the presence of $\mathrm{Mg}, \mathrm{Si}$ and $\mathrm{O}$ arising from the body of the crystals. A minor contribution arises from iodine, which cannot be specifically located within the crystal body with EDX mapping analysis. However, EDX spot and mapping analysis of the particles located beneath the forsterite crystals, reveal that they contain $\mathrm{Mg}, \mathrm{Si}$ and $\mathrm{O}$, with a minor contribution arising from iodine. Quantitative analysis shows the distribution of elements Mg:Si:O:I to vary from area to area. For example, one ratio was found to be 24:17:59:0 (iodine being a negligible fraction), which implied the presence of $\mathrm{Mg}_{2} \mathrm{SiO}_{4}$ and $\mathrm{SiO}_{2}$.

Another area revealed smaller particles located beneath the forsterite crystal leaves (figure 4). These particles exhibit a spiked morphology (observable in both SEM and TEM images) and vary widely in size. Electron diffraction of these particles (figure 5(b) inset) reveals numerous reflections corresponding to the formation of multi-directional crystalline domains, leading to difficulty in indexing the pattern. EDX mapping also revealed the presence of $\mathrm{Mg}, \mathrm{Si}$ and $\mathrm{O}$ arising from the body of the particles and quantitative analysis showed a higher presence of iodine, in the order 54:12:31:3 (Mg:Si:O:I). When subtracting the contribution of $\mathrm{Mg}_{2} \mathrm{SiO}_{4}$, the remainder 25:30 fraction implies the sample comprising $\mathrm{Si}, \mathrm{SiO}$ and $\mathrm{SiO}_{2}$ and still leaves the contribution from I. However, no free iodine was isolated from the substrate after the reaction had completed, when washed with toluene. Although a brown deposit on the tip end of the reaction tube turned into a liquid on exposure to (moist) air over time, presumably due to the hydration of $\mathrm{MgI}_{2}$ crystals formed at the cooler end of the reaction vessel and the colouration
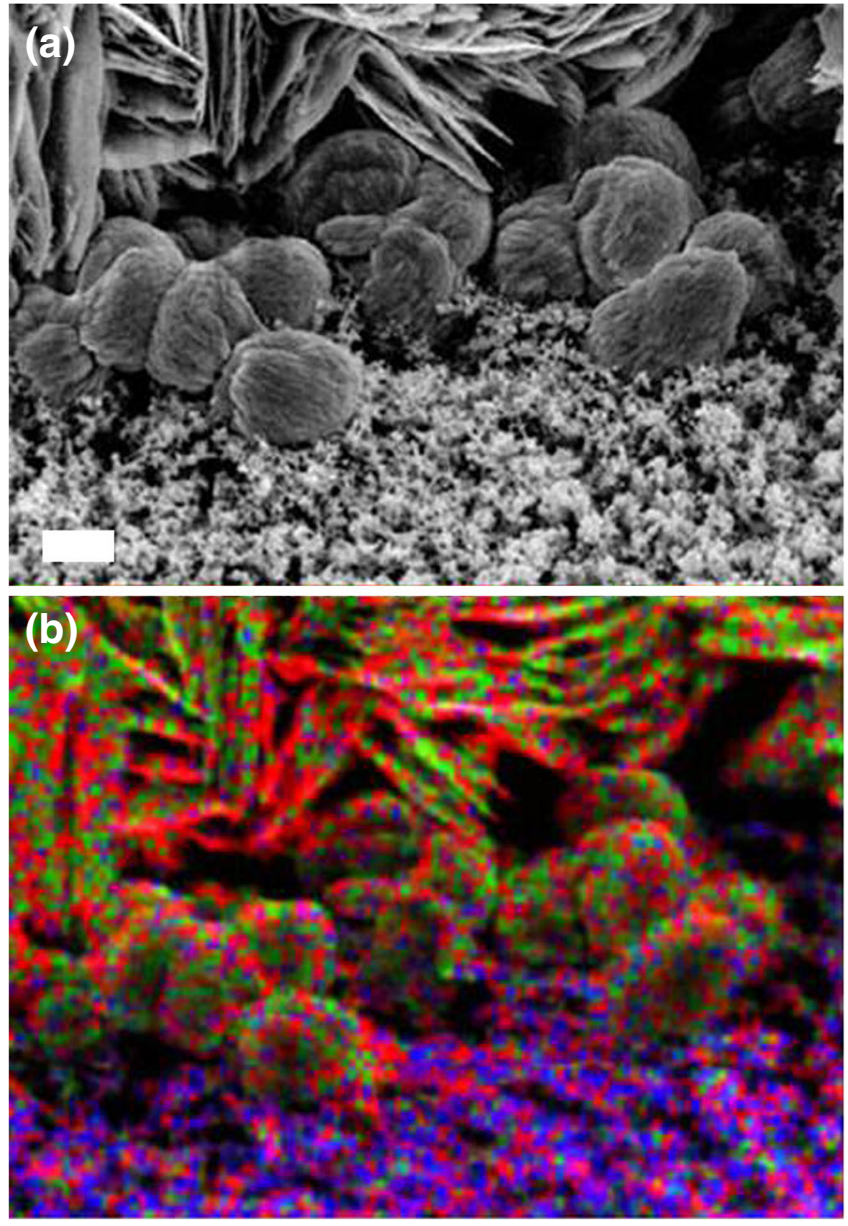

Figure 4. (a) SEM image of the spiked-morphology of the smaller 'precursor' forsterite particles and (b) corresponding EDX mapping analysis (scale bar $=1 \mu \mathrm{m}$ ). 


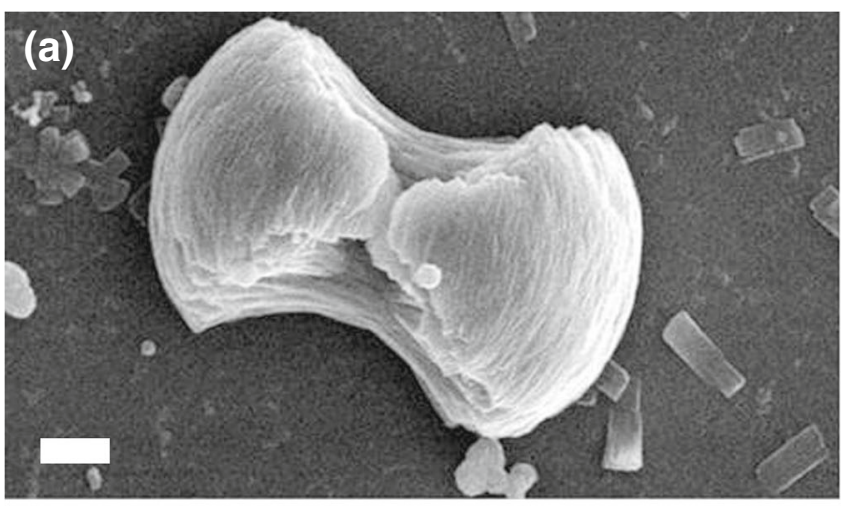

(b)

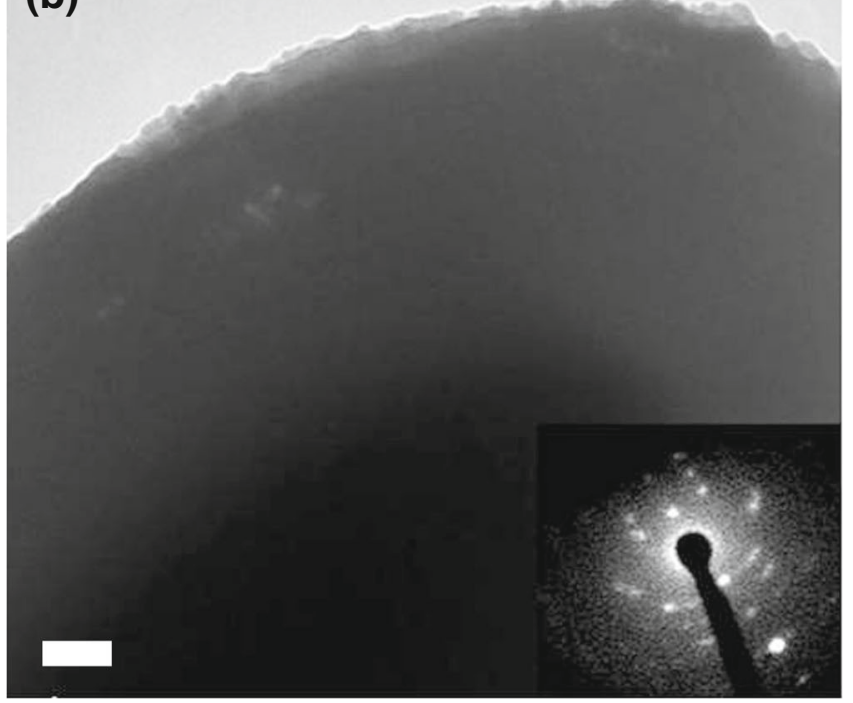

Figure 5. (a) SEM image of the forsterite precursor particle and (b) the corresponding TEM image and SAED (inset) (scale bars = $250 \mathrm{~nm}$ and $10 \mathrm{~nm}$ respectively).

resulting from the dissolution of free iodine. From the electron diffraction pattern (figure 2c) and computer simulations (not shown), it is evident that the substrate crystal samples are consistent with that of crystalline forsterite.

\subsection{Architecture}

The initial deposit of $\mathrm{SiO}_{2}$ on the quartz substrate comprises agglomerated particles, ca. $3 \mu \mathrm{m}$ in diameter, from which $\mathrm{SiO}_{2}$ is changed towards a magnesium silicate composition that bears a spiked appearance (figure $4 \mathrm{a}$ ) and resembles a stunted form of the cabbage-like structures. As the reaction proceeds further, the spiked areas in the incipient magnesium silicate particle provide the regions for the forsterite crystal to grow away from the particle's core into the final cabbage-like structure.

The variety of crystal dimensions and morphology can be observed in figure 6 . Within the dense mass of crystal leaves, the sides of the crystal bodies are observed to lie at right angles to other leaf crystals (arrow A) or with other leaves or sub-structures propping the supported leaf (arrows B and C). Therefore, the close-packed arrangement of leaf crystals that
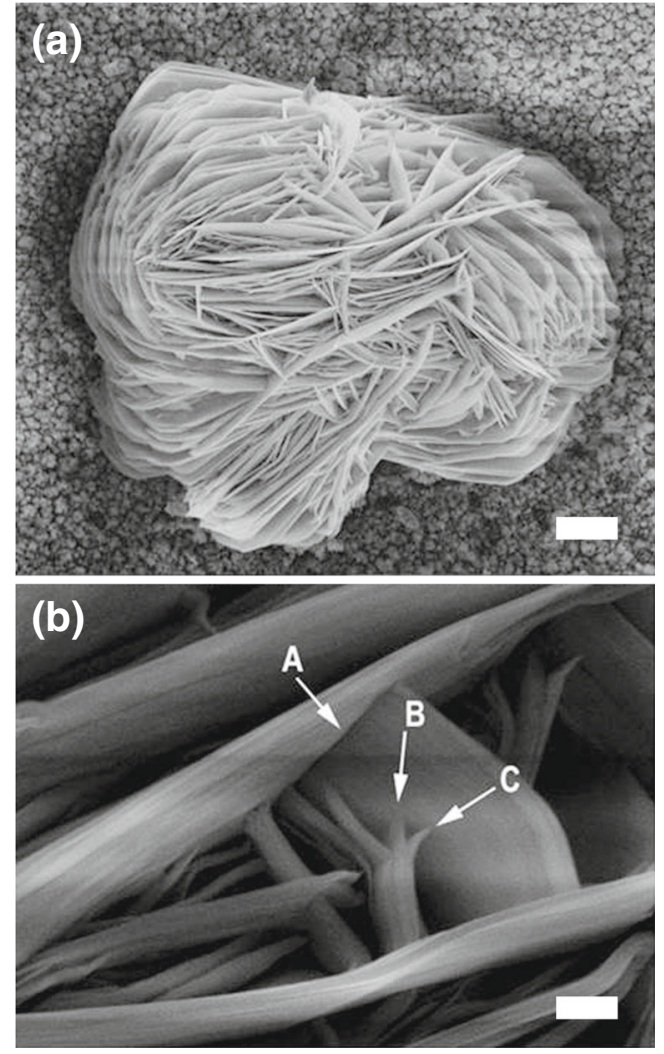

Figure 6. (a) SEM image of a cabbage-like structure and (b) a higher magnification image revealing the interaction of crystal leaves aiding support to the overall structure (scale bar $=3 \mu \mathrm{m}$ and $10 \mathrm{~nm}$ respectively).

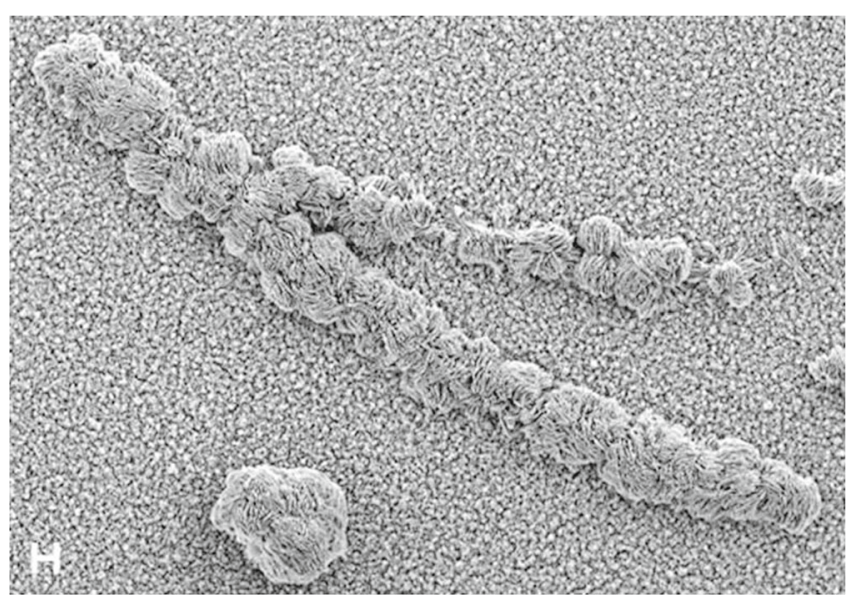

Figure 7. A branched forsterite crystal system (scale bar = $10 \mu \mathrm{m})$.

lends to the stability of the overall structure. These cabbagelike structures do not grow solely independently but sometimes in close proximity to other structures allowing for the interaction of neighbouring crystal systems. Figure 7 shows a linear cluster of forsterite crystals, resulting from twelve or more cabbage-like macro structures forming together without showing any visible signs of separation along the lower 


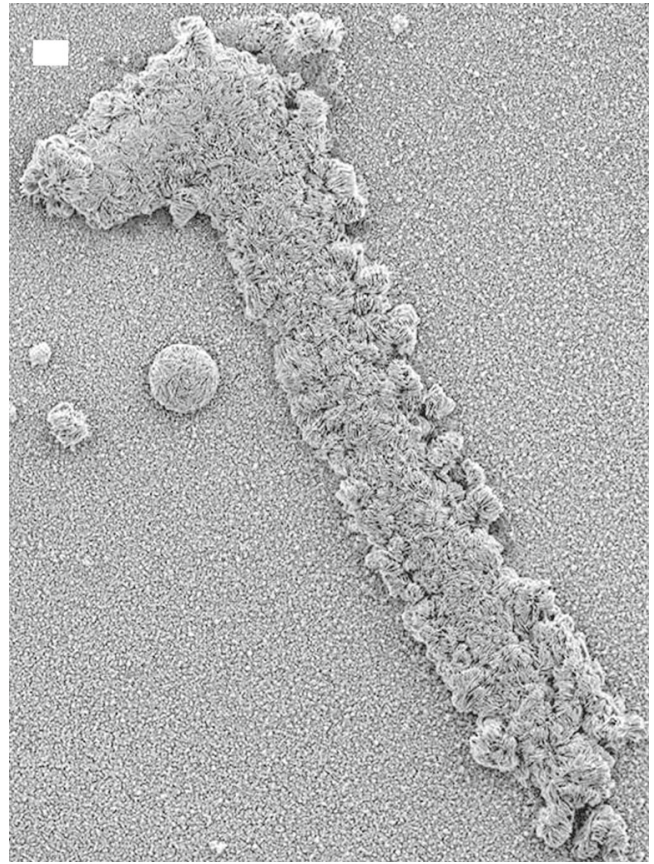

Figure 8. An extensive growth structure of forsterite crystals (scale bar $=20 \mu \mathrm{m}$ ).

branch. Although the division from the main body to the upper branch is seamless, the upper crystal branch grows discontinuously.

Figure 8 shows a comprehensive structure of numerous interconnecting forsterite crystals. The structure is over $0.5 \mathrm{~mm}$ in length, observable lying on the substrate with the naked eye. Figure 9 reveals another example of an elaborate series of forsterite macro-structures growing together. In this instance the structure actually radiates away from the template and overhangs the surface, evident from the rotational SEM images provided. The structure is completely selfsupported and relies solely on the interaction of leaf crystals, although it would seem likely that a common shared core between each macro-structure may be present (not observed in this study). The structure freely overhangs the substrate by around $250 \mu \mathrm{m}$ at its highest point and was again observable with the naked eye. Whilst several other linear crystals were observed in the sample, no other overhanging structures were found elsewhere on the substrate.

\subsection{Formation mechanism}

In order to elucidate the underlying mechanism, the following reactions are put forward based upon the role of $\mathrm{MgO}$ in the literature:

$$
\begin{aligned}
& \mathrm{Mg}_{(\mathrm{g})}+\mathrm{SiO}_{2(\mathrm{~s})} \rightarrow \mathrm{MgO}_{(\mathrm{s})}+\mathrm{SiO}_{(\mathrm{g})}, \\
& 2 \mathrm{MgO}_{(\mathrm{s})}+\mathrm{SiO}_{2(\mathrm{~s})} \rightarrow \mathrm{Mg}_{2} \mathrm{SiO}_{4(\mathrm{~s})}, \\
& 2 \mathrm{Mg}_{(\mathrm{g})}+4 \mathrm{SiO}_{(\mathrm{g})} \rightarrow \mathrm{Mg}_{2} \mathrm{SiO}_{4(\mathrm{~s})}+3 \mathrm{Si}_{(\mathrm{s}, \mathrm{l})} .
\end{aligned}
$$
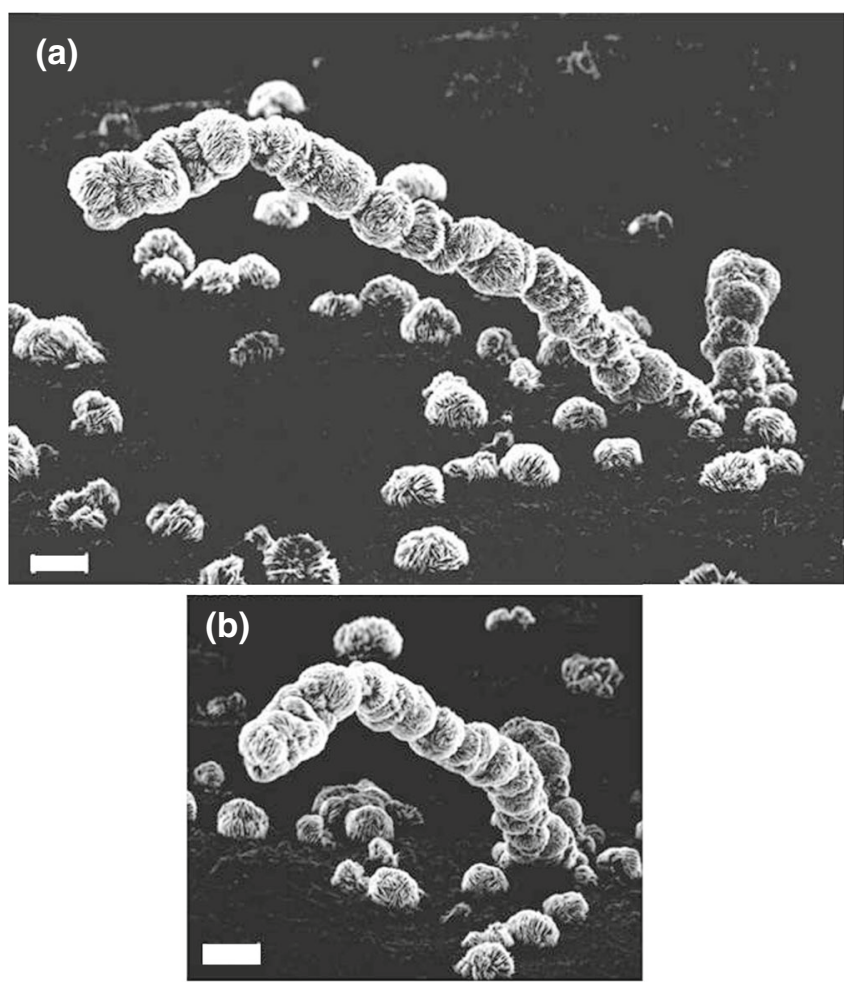

Figure 9. (a-b) Rotational SEM images of an overhanging forsterite structure (scale bar $=50 \mu \mathrm{m}$ ).

Given that the boiling point of magnesium is ca. $1103{ }^{\circ} \mathrm{C}$, the transport of magnesium down the length of the reaction tube must occur through iodine vapour. As an inert atmosphere was utilised, the oxidation of magnesium is made possible through step (1) although magnesium would be in the liquid phase suspended in iodine vapour. This reduces the surrounding silicon oxide deposit to a lesser species (either $\mathrm{SiO}$ or $\mathrm{Si}$ ). The reaction would then follow a solid-solid species diffusion process, according to step (2), giving rise to the final product. However, a stationary solid-solid reaction would result in the localised formation of forsterite crystals (Tsai 2003) and would not account for the formation of over-hanging structures as observed in figure 9 . It is deduced that both $\mathrm{Mg}(\mathrm{O})$ and $\mathrm{SiO}_{2}$ species are mobile in the forsterite crystal formation.

The potential involvement of $\mathrm{SiO}$ in step (1) could also promote another reaction occurring directly with $\mathrm{Mg}$ to form forsterite (step 3), but $\mathrm{SiO}$ may also further dissociate into $\mathrm{Si} / \mathrm{SiO}_{2}$ at such elevated temperatures. Currently, the only indication that $\mathrm{SiO}$ and $\mathrm{Si}$ may be present in the sample comes from the results of the quantitative analysis of the 'spikey' precursor particles. Further investigations are proceeding to establish whether the core of these cabbage-like crystals contains a uniform forsterite crystal composition akin to the leaf crystals or whether it changes towards pure Si.

Figures 10(a) and (b) show a quartz substrate, with a cross etched into the silicon oxide deposit, before and after the reaction $\left(800-600^{\circ} \mathrm{C}\right.$ for 1 day). In the before state, it is clear 

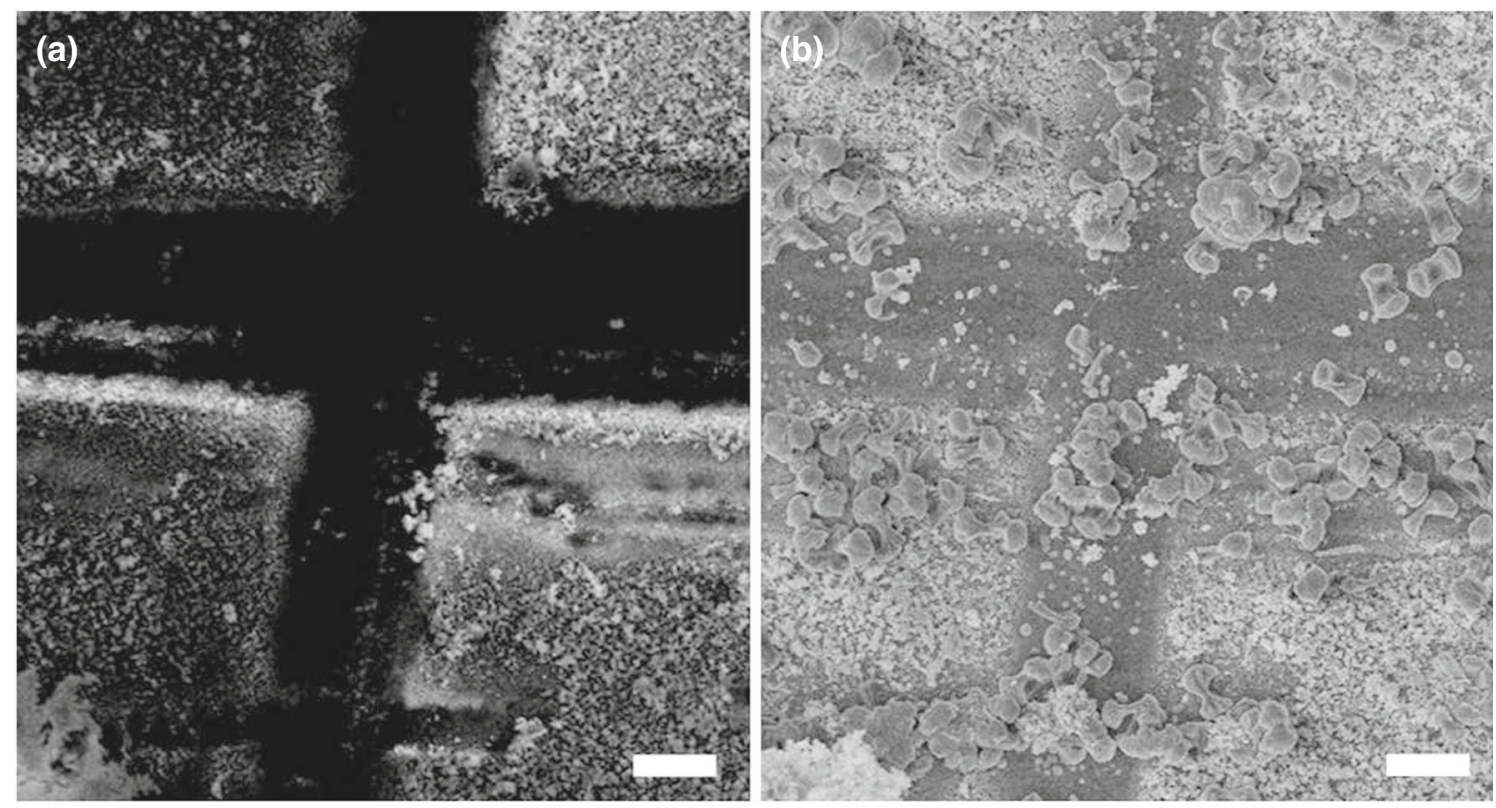

Figure 10. (a) before and (b) after SEM images of a pre-etched substrate revealing a lack of correlation between the initial $\mathrm{SiO}_{2}$ deposit and the final position of the forsterite particles (scale bar $=30 \mu \mathrm{m}$ ).

that the silicon oxide particles are no bigger than ca. $1 \mu \mathrm{m}$ in diameter. In the after state, the etched channel formed is much shallower and a number of large spiked particles, between 5 and $8 \mu \mathrm{m}$ across, have proliferated. It is apparent, therefore, that no template mechanism is operating between the initial silicon oxide particles and the final $\mathrm{Mg}_{2} \mathrm{SiO}_{4}$ crystals. Rather, the amorphous layer of silicon oxide is depleted from the area surrounding the crystal growth site and reacts with the formed $\mathrm{MgO}$ in step 2, or is reduced to $\mathrm{SiO}$ and reacts with $\mathrm{Mg}$ in step 3, to form forsterite. The depletion of silicon oxide results in the shallowing of the etched channels, as mentioned earlier.

In subsequent experiments the temperature was increased to $1000-800^{\circ} \mathrm{C}$, which completely suppressed the formation of the cabbage-like crystals. Also the ratio of magnesium to iodine was varied with all other conditions kept the same. The increase in iodine to magnesium ratio retards the proliferation of the crystal leaves radiating from the core structure after prolonged heating and solely spiked particles are observed. It is apparent that iodine must influence this incipient structure towards creation of a spiked morphology that extends into the cabbage-like structures during prolonged heating.

In a separate experiment (using $\mathrm{Mg}$ and $\mathrm{I}_{2}$ starting materials) in which the temperature range was lowered to $600-400{ }^{\circ} \mathrm{C}$, no $\mathrm{Mg}_{2} \mathrm{SiO}_{4}$ cabbage-like crystals were observed. Instead quantities of white hygroscopic crystals were obtained from the substrate and reaction tube walls, which EDX/quantitative analysis showed to be consistent with that of $\mathrm{MgI}_{2}$. When $\mathrm{MgI}_{2}$ (Aldrich $99.8 \%+$ ) was solely used as the starting material (for the temperature range $800-600{ }^{\circ} \mathrm{C}$ ) only one $\mathrm{Mg}_{2} \mathrm{SiO}_{4}$ spiked particle was observed in the final sample along with a single magnesium particle on the substrate. Herein the substrate remained white in colouration.

When the temperature range was increased to $800-700^{\circ} \mathrm{C}$, utilising $\mathrm{Mg}$ and $\mathrm{I}_{2}$ as starting materials, numerous spiked particles were still observed on the grey-brown substrate. In this instance, the entire reaction tube was above the decomposition temperature of $\mathrm{MgI}_{2} \mathrm{ca} .637^{\circ} \mathrm{C}$ in an attempt to prevent its formation during the forsterite crystal growth. However, only spiked particles and not cabbage-like crystals were observed after $24 \mathrm{~h}$ of heating. Whilst the spiked morphology can be linked to the involvement of iodine, the role of $\mathrm{MgI}_{2}$ in the proliferation of leaf-like forsterite crystals in the cabbage-like structures cannot be wholly excluded at this time.

In additional experiments, when the lower temperature was increased from 600 to $700{ }^{\circ} \mathrm{C}$ and utilising $\mathrm{Mg}$ and $\mathrm{I}_{2}$ as starting materials, numerous spiked particles were still observed on the substrate. In this instance the entire reaction tube was above the decomposition temperature of $\mathrm{MgI}_{2}$ ca. $637^{\circ} \mathrm{C}$ in an attempt to prevent its formation during the forsterite crystal growth. However, only spiked particles and not cabbage-like crystals were observed after $24 \mathrm{~h}$ of heating. When $\mathrm{MgI}_{2}$ (Aldrich $99.8 \%+$ ) was solely used as the starting material for the temperature gradient range $800-600{ }^{\circ} \mathrm{C}$, no spiked particles or crystals were observed in the final sample. Further experiments showed that, when the temperature gradient range was increased to $1000-800^{\circ} \mathrm{C}$, the formation of the cabbage-like crystals was completely suppressed. Also the ratio of magnesium to iodine was varied with all other conditions kept the same. The increase in iodine to magnesium ratio retards the proliferation of the crystal leaves 
radiating from the core structure after prolonged heating and solely spiked particles are observed. It is apparent that iodine must influence this incipient structure towards creation of a spiked morphology that extends into the cabbage-like structures during prolonged heating. It is also determined that the role of $\mathrm{MgI}_{2}$ in the proliferation of leaf-like forsterite crystals in the cabbage-like structures does not appear likely.

In a subsequent test we conducted experiments using a pre-etched cross in the silicon oxide deposit prior to reaction (details not shown). In the before state, silicon oxide particles are observed to be no bigger than ca. $1 \mu \mathrm{m}$ in diameter. In the after state, the etched channel formed is much shallower and a number of large spiked particles, between 5 and $8 \mu \mathrm{m}$ across, have proliferated. There is no correlation in size or location between the initial deposit of $\mathrm{SiO}_{2}$ particles and the final forsterite structures. It is evident that no template mechanism is operating between the initial deposit during the reaction and the final structure. Rather, the amorphous layer of silicon oxide is depleted from the area surrounding the crystal growth site and reacts with the formed $\mathrm{MgO}$ in step (2), or is reduced to $\mathrm{SiO}$ and reacts with $\mathrm{Mg}$ in step (3), to form forsterite.

In repeating the experiment with iron, instead of magnesium, and under the same conditions we were able to generate fayalite crystals. The 'Stonehenge' example shows the distribution of fayalite crystals on the substrate after the experiment, bearing octagonal cross-section geometry with a greater depth than the leaf-like forsterite crystals (figure 4, upper). The overall length and depth of these fayalite crystals vary from 1 to $15 \mu \mathrm{m}$. The crystals appear to have formed in close proximity to each other and can be divided into distinct regions, where the crystals within each region point in a fairly even direction towards the centre of the region where a set of larger fayalite crystals are located. Again, there was a lack of size and location correlation between the initial silicon oxide deposit and the final crystals. The silicon oxide layer has undergone part depletion and the remaining deposit has maintained a particulate nature, whilst the fayalite crystals have stacked in close proximity, resembling the Giant's Causeway (Co. Antrim, Ireland) or the Oni no Sentaku Iwa Giant's Washboard (Miyazaki, Japan) (figure 4, lower). This reinforces the idea that both $\mathrm{Fe}(\mathrm{O})$ and $\mathrm{SiO}_{2}$ species were mobile during fayalite synthesis.

\section{Conclusions}

The iodine vapour transport experiments of magnesium and iron onto silicon oxide have revealed olivine nano- and micro-sized crystal formation with remarkable macro-scale architecture. Whilst the detailed mechanism is still elusive, it is deduced that both $\mathrm{Mg}(\mathrm{O}) / \mathrm{Fe}(\mathrm{O})$ and $\mathrm{SiO}_{2}$ species are mobile and diffuse together in the presence of iodine to form these cabbage-like structures.

\section{Acknowledgements}

We thank the EU FP7 International Research Staff Exchange Scheme (ENSOR-269267).

\section{References}

Brindley G W and Hayama R 1965 Phil. Mag. 12505

Burlitch J M, Beeman M L, Riley B and Kohlstedt D L 1991 Chem. Mater. 3692

Faure F, Trolliard G and Soulestin B 2003 Am. Mineralogist 88 1241

Jander W and Wuhrer J 1936 Z. Anorg. Chem. 226225

Kamran A H R, Moztarzadeh F, Mozafari M, Azami M and Baghbani F 2011 Adv. Comp. Lett. 2049

Kazakos A, Komarneni S and Roy R 1990 Mater. Lett. 9405

Mitchell M B D, Jackson D and James P F 1999 J. Sol-Gel Sci. Tech. 15211

Rimmington H P and Balchin A A 1974 J. Cryst. Growth 21171

Tavangarian F and Emadi R 2011 Ceramics Int. 372543

Tsai M T 2003 J. Eur. Ceram. Soc. 231283

Whitby R L D, Brigatti K S, Kinloch I A, Randall D P and Maekawa T 2004 Chem. Comm. 212396

Xie S, Zhou W and Zhu Y 2004 J. Phys. Chem. B 10811561

Yamaguchi O, Nakajima Y and Simazu K 1976 Chem. Lett. 5401

Zhang Z, Wong L M, Wang H X, Wei Z P, Zhou W, Wang S J and Wu T 2010 Adv. Fun. Mater. 202511 